\title{
Регенерируемые сорбенты на основе полипиррола для очистки водных сред от микропатогенов
}

\author{
Морозова Е.О. ${ }^{1}$, Кулик Е.А. ${ }^{2}$, Сапурина И.Ю. ${ }^{3}$, Николаева Т.Н. ${ }^{1}$, \\ Бурцева Е.И. ${ }^{1}$, Пронин А.В. ${ }^{1}$, Иванова В.Т. ${ }^{1}$ \\ ${ }^{1}$ Институт вирусологии им Д.И. Ивановского ФГБУ «НИЦЭМ им. Н.Ф. Гамалеи» \\ Минздрава России, Москва \\ ${ }^{2}$ ФГАОУ ВО Первый МГМУ имени И. М. Сеченова Минздрава России, Москва \\ ${ }^{3}$ Институт высокомолекулярных соединений РАН, Санкт-Петербург
}

Поступила в редакцию 29.05.2019 г.

DOI: https://doi.org/10.17308/sorpchrom.2019.19/777

Исследована сорбция новым поколением полимерных сорбентов ( полипирролом и полипирролом, модифицированным наночастицами серебра) различных типов микропатогенов: пандемического штамма вируса гриппа A/Южная Каролина/02/2010 (H1N1)pdm09, а также бактерий (грамположительных Staphylococcus aureus и грамотрицательных Shigella flexneri) Установлено, что сорбенты не только обладают эффективной первичной сорбцией, но также могут быть регенерированы. Эффективность вторичной сорбции зависела от типа сорбента и вида микропатогена. Способность к регенерации сорбента выше в случае бактерий, чем при взаимодействии с вирусом.

Ключевые слова: сорбция, полипиррол, вирусы гриппа, бактерии, регенерация сорбента.

\section{Polypirrole-based regenerated sorbents for the purifica- tion of aqueous media from micropathogens}

\author{
Morozova E.O. ${ }^{1}$, Kulik E.A. ${ }^{2}$, Sapurina I.Yu. ${ }^{3}$, Nikolaeva T.N. ${ }^{1}$, \\ Burtseva E.I. ${ }^{1}$, Pronin A.V. ${ }^{1}$, Ivanova V.T. ${ }^{1}$ \\ ${ }^{I}$ D.I. Ivanovsky Institute of Virology FSBI «N.F. Gamaleya NRCEM»MoPH \\ of the Russian Federation, Moscow \\ ${ }^{2}$ I.M. Sechenov First Moscow State Medical University, Moscow \\ ${ }^{3}$ Institute of Macromolecular Compounds, Russian Academy of Sciences, Saint-Petersburg
}

In continuation of a series of studies on a new generation of microbathogen sorbents based on electrically conductive polymers: polyaniline and polypyrrole, the possibility of regeneration and reuse of polypyrrole for water purification through the sorption of bacteria and viruses from aqueous media was investigated. For example, the binding of polypyrrole and polypyrrole modified with silver nanoparticles of the pandemic influenza virus strain A/South Carolina / 02/2010 (H1N1) pdm09 and epidemiologically and pathogenetically significant bacteria: Staphylococcus aureus (Gram +) and Shigella flexneri (Gram -) shown:

During primary sorption, sorbents almost completely neutralize concentrated virus solutions (GAE 512 ) and epidemically dangerous solutions of bacteria with CFU $2 \cdot 10^{5}$.

- Sorbent regeneration consists of a short-term warming up in an aquatic environment with subsequent exposure to ultrasound.

- Secondary sorption of micropathogens leads to almost complete removal of Staphylococcus, and a significant decrease in the concentration of Shigella and viruses

The results indicate the possibility of repeated, and possibly repeated use of sorbents. The advantages of these sorbents in their use for the purification of aqueous media from biological contaminants are: 1 . the 
ability to effectively sorb a wide range of micropathogens: both bacteria and viruses; 2 . suppression of the infectious activity of associated micropathogens, i.e. complete infectious safety of the sorbent + pathogen complexes; 3. possibility of regeneration and repeated use of the sorbent. At the same time, the sorbents themselves are non-toxic and relatively cheap.

Keywords: sorption, polypyrrole, influenza viruses, bacteria, temperature and ultrasonic treatment.

\section{Введение}

Очистка водных сред от микропатогенов - возбудителей опасных инфекционных заболеваний, является важной составляющей противоэпидемических мер защиты населения. Различные неорганические материалы типа активированных углей, цеолитов и монтморилонитов, обладающих высокой пористостью и большой удельной площадью поверхности, используют в качестве сорбентов различного рода загрязнений. Пористые структуры способны поглощать широкий спектр нефтехимических продуктов, а также сорбировать микропатогены. Сорбция имеет неспецифический характер. Сорбционные свойства данных материалов реализуются благодаря наличию пор и слабых Ван-дер-Ваальсовых взаимодействий. Исследования на бактериях Escherichia coli 987p и Salmonella показали, что модификация данных сорбентов соединениями, содержащими ионы $\mathrm{Ag}, \mathrm{Li}$ и $\mathrm{Zn}$, позволяет усилить их бактерицидную активность. Однако такие сорбенты достаточно дорогие. Недостатками более дешевых сорбентов, содержащих включения $\mathrm{K}, \mathrm{Na}, \mathrm{Mg}$, а также лекарственные препараты на основе природных материалов типа неосмектина и смекты, в том, что они хоть и сорбируют бактерии, но не подавляют их рост и развитие [1].

В настоящее время актуальна разработка нового поколения сорбентов для очистки воды, предотвращающих распространение бактериальных и вирусных инфекций водным путем. К новому поколению сорбентов относятся электропроводящие полимеры: полианилин и полипиррол (РРу). По составу полимеры сходны с биологическими материалами и имеют специфическое химическое сродство к биообъектам. Помимо этого электропроводящие полимеры обладают биосовместимостью, поэтому интенсивно исследуются в сфере биомедицинских применений как invitro, так и in-vivo [2, 3]. В тоже время, электропроводящие полимеры термостабильны, практически нерастворимы и могут быть получены в виде различных типов морфологий с большой удельной площадью поверхности [4], что необходимо для повышения емкости сорбента. Наличие в полимерных цепях системы полисопряжения и гетероатомов азота обуславливает возможность специфических сорбционных взаимодействий. Возможность связывания полипирролом различных типов биологических объектов описана в работах [5]. РРу способен сорбировать белки [6,7] и ДНК [8] за счет ионных взаимодействий, образования комплексов, а иногда и в результате ковалентного связывания [5]. Показано, что мембраны на основе РРу позволяют удалять из водных сред ряд вирусов животных, включающих полиовирусы, коксаки, эхо, и другие энтеровирусы, рео, рота, гепатит А [9].

В серии предыдущих работ нашего коллектива показано, что полисопряженный РРу, а также его композиты с наночастицами серебра (РPy-Ag), активно сорбируют из водных сред вирусы гриппа А и В, полиовирусы (вакцинный штамм полиомиелита Сэбина 1-го типа), а также ряд грамположительных и грамотрицательных бактерий $[10,11]$. Сорбция происходит с высокими скоростями в условиях, воспроизводящих реальные: в диапазоне температур $4-22^{\circ} \mathrm{C}$ и в присутствии белков непатогенной природы. Показано также, что сорбция на РРу полностью подавляет инфекционную активность вирусов, т.е. комплекс «сорбент+вирус» становится инфекционно не опасным [12]. Все это говорит о перспективности практического применения полимерных сорбентов. Данное исследование посвящено поиску возможностей 
повышения сорбционной активности РРу и $\mathrm{PPy}-\mathrm{Ag}$, а также разработке метода регенерации сорбентов для их повторного применения.

\section{Эксперимент}

В работе использованы следующие типы микропатогенов:

Вирусы. Представитель оболочечных вирусов пандемический штамм вируса гриппа А/Южная Каролина/02/2010 (H1N1), антигенные варианты которого циркулируют в мире с 2010 г. по настоящие время. Вирус получен из коллекции вирусов гриппа лаборатории экологии и эпидемиологии гриппа Института вирусологии им. Д.И. Ивановского ФГБУ «НИЦЭМ им Н.Ф. Гамалеи» Минздрава России. Вирус культивировали в аллантоисной полости куриных эмбрионов, после чего его ресуспензировали и исследовали в физиологическом растворе (ФР).

Бактерии. Условно-патогенные микроорганизмы - грамположительные (Грам +) Staphylococcus aureus, а также эпидемиологически и патогенетически значимые грамотрицательные (Грам - ) Shigella flexneri бактерии. Бактерии получены из коллекции микроорганизмов лаборатории естественного иммунитета ФГБУ «НИЦЭМ им. Н.Ф. Гамалеи» Минздрава России.

Сорбенты. Полипиррол (РРу) получен одностадийным методом окислительной полимеризации пиррола $(0.2 \mathrm{M})$ в водном растворе подкисленном серной кислотой $(0.1 \mathrm{M})$ с использованием в качестве окислителя сульфата трехвалентного железа $(0.4 \mathrm{M})$. Полипиррол, модифицированный наночастицами серебра, (PPy-Ag) получен путем высаживания наночастиц серебра на полимерную матрицу из водного раствора соли $\mathrm{AgNO}_{3}$. Содержание серебра в РPу-Ag составляет 10-15\% массы композита.

Активацию сорбентов с целью повышения сорбционной активности РРу и $\mathrm{PPy}-\mathrm{Ag}$ проводили путем прогрева порошков сорбентов в термостате «СНВС4.5.4.5.4/3И-1» в воздушной среде при $100^{\circ} \mathrm{C}$ в течение 30 или 60 минут по схеме, представленной на рис. 1 [10].

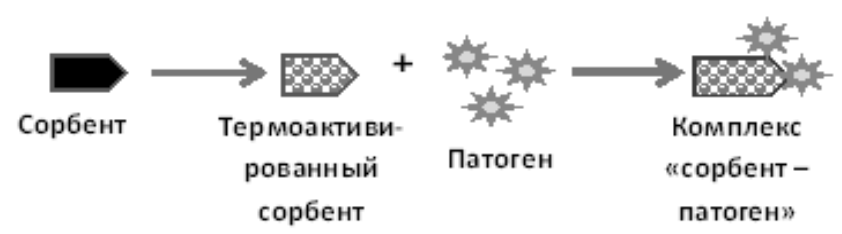

Рис. 1. Схема сорбции патогенов на термоактивированный сорбент

Стандартная процедура исследования сорбционной активности состояла из следующих этапов: 1. - приведения в контакт сорбента (4 мг) с биологическими патогенами в ФP ( $\mathrm{v}=200$ мкл) путем перемешивания на орбитальном шейкере в течение 20 мин при $22^{\circ} \mathrm{C}$; 2.- выделения комплекса «сорбент+патоген» посредством низкоскоростного центрифугирования при 3000 об/мин в течение 5 минут и 3. - анализа водной среды «надосадка» на присутствие патогенна путем определения титра патогенна по известной методике.

Регенерацию сорбентов проводили согласно схеме, представленной на рис.2. После первичной сорбции микропатогенов она осуществлялась путем редиспергирования комплекса «сорбент+патоген» (4 мг), выделенного низкоскоростным центрифугированием, в новой порции ФР (v=200 мкл), прогрева его при $100^{\circ} \mathrm{C}$ в течение 30 или 60 мин с последующим использованием ультразвука «Bransonic 12» при рабочей частоте 40 кГц в течение 15 мин и последующего выделения сорбента низкоскоростным центрифугированием для проведения вторичной сорбции. 


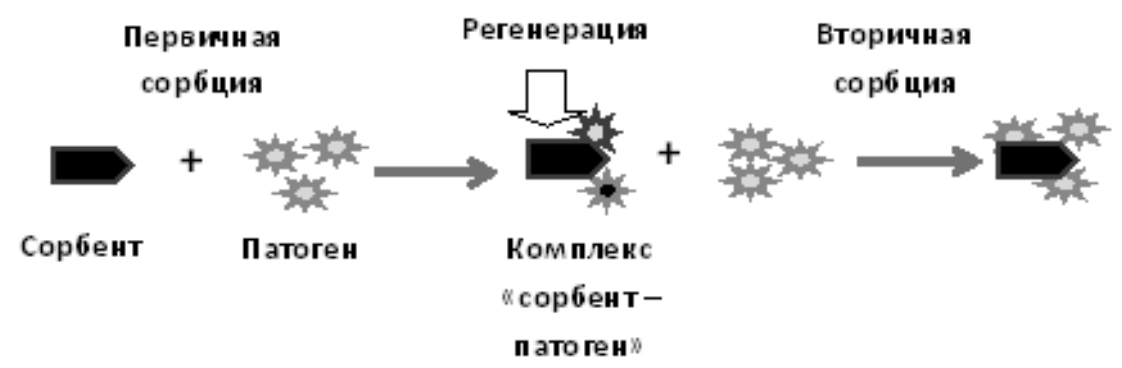

Рис. 2. Схема: первичная сорбция патогенов с формированием комплекса «сорбент - патоген», регенерация комплекса и последующая вторичная сорбция микропатогенов. на регенерированный сорбент

Исследование сорбционных взаимодействий проводили на (1) - исходных, как прогретых, так и непрогретых сорбентах; (2) - на комплексах «сорбент+патоген» до регенерации; и (3) - на комплексах «сорбент+патоген» после их регенерации путем прогрева и ультразвукового воздействия.

Для оценки эффективности сорбции сопоставляли титры микроорганизмов в ФР до и после их контакта с сорбентами. В случае вирусов определяли гемагглютинирующие (ГА) титры в реакции гемагглютинации по методике, рекомендованной ВО3, с использованием $0.75 \%$ взвеси эритроцитов 0(I) группы крови человека. В случае бактерий титры КОЕ (колония образующих единиц) по методике количественного определения жизнеспособных бактерий на питательной среде ( $2 \%$ питательный агар - Nutrient agar, Himedia J).

\section{Обсуждение результатов}

Термоактивация РРу и РPу-Ag с целью повышения сорбционной активности. Ранее, при исследовании сорбционных свойств полианилина, было установлено, что предварительный прогрев порошкообразного сорбента в термостате при температуре $100^{\circ} \mathrm{C}$ в течение 30 мин несколько уменьшал его сорбционную емкость по отношению к вирусам гриппа и не влиял на сорбционную активность РРу [12]. Целесообразно было проверить, как влияет подобная термообработка на сорбционные свойства в сравнительном аспекте РРу и РРy-Ag относительно патогенов с разной структурой (вирусы и бактерии).

В таблице 1 представлены результаты исследования сорбционной активности PРy и PРy-Ag до и после термообработки при $100^{\circ} \mathrm{C}$ в течение 30 и 60 минут. Видно, что вне зависимости от термообработки РРу полностью сорбирует и вирусы, и бактерии, т.е. предел его сорбционной емкости при данном соотношении патоген/сорбент не достигнут. Из данных таблицы 2 (результат 1,3 ) следует, что при введении новой порции вирусов на комплекс «сорбент+вирус» имеет место дополнительная сорбция вируса и снижение его титра с 512 до 32 ГАЕ.

В случае PРy-Ag сорбционная емкость в отношении вирусов несколько ниже, чем у РРу. Она близка к предельной уже при первичной сорбции вируса (таблица 1, результат 2), несколько повышается при предварительном прогреве PPy-Ag в течение 30 мин (таблица 1, результат 4), а при часовом прогреве вновь снижается (таблица 1, результат 6). В отношении бактерий сорбционная активность РРу и PРy-Ag высокая, связывание бактерий полное вне зависимости от прогрева. 
Таблица 1. Влияние прогревания сорбентов - композитов РРу на активность взаимодействия с микроорганизмами

\begin{tabular}{|c|c|c|c|c|c|c|c|c|}
\hline \multirow{2}{*}{ № } & \multirow{2}{*}{$\begin{array}{l}\text { Cop- } \\
\text { бент }\end{array}$} & \multirow{2}{*}{$\begin{array}{c}\text { Термооб- } \\
\text { работка } \\
100^{\circ} \mathrm{C}, \\
\text { мин }\end{array}$} & \multirow{2}{*}{ Вирус } & \multicolumn{2}{|c|}{\begin{tabular}{|c|} 
Tитр вируса, \\
ГАЕ \\
\end{tabular}} & \multirow{2}{*}{ Бактерия } & \multicolumn{2}{|c|}{$\begin{array}{c}\text { Титр бактерии } \\
\text { КОЕ/см }\end{array}$} \\
\hline & & & & $\begin{array}{c}\text { до } \\
\text { сорбции }\end{array}$ & $\begin{array}{c}\text { после } \\
\text { орбции }\end{array}$ & & $\begin{array}{c}\text { до } \\
\text { сорбции }\end{array}$ & $\begin{array}{r}\text { после } \\
\text { сорбции }\end{array}$ \\
\hline 1 & PPy & \multirow[t]{2}{*}{ 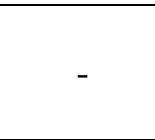 } & \multirow{6}{*}{$\begin{array}{l}\text { А/Южная Ка- } \\
\text { ролина/02/2010 }\end{array}$} & \multirow{6}{*}{512} & \begin{tabular}{l|}
0 \\
\end{tabular} & \multirow{6}{*}{$\begin{array}{l}\text { Staphylococcus } \\
\text { aureus Cowan }\end{array}$} & \multirow{6}{*}{$2 \cdot 10^{5}$} & 0 \\
\hline 2 & $\begin{array}{l}\text { PPy- } \\
\mathrm{Ag}\end{array}$ & & & & $4-8$ & & & 0 \\
\hline 3 & PPy & \multirow[b]{2}{*}{30} & & & 0 & & & 0 \\
\hline 4 & $\begin{array}{l}\text { PPy- } \\
\text { Ag }\end{array}$ & & & & 0 & & & 0 \\
\hline 5 & PPy & \multirow[b]{2}{*}{60} & & & 0 & & & 0 \\
\hline 6 & $\begin{array}{l}\mathrm{PPy}- \\
\mathrm{Ag}\end{array}$ & & & & 4 & & & 0 \\
\hline
\end{tabular}

Ожидалось, что термообработка повысит удельную площадь поверхности сорбента за счет выделения из полимерной матрицы воды и низкомолекулярных допирующих агентов, что сопровождается увеличением свободного объема и формированием системы пор в теле полимера. Исследование показало лишь незначительное повышение сорбционной емкости $\mathrm{PPy}-\mathrm{Ag}$ при кратковременной термообработке. Возможно, различие результатов, полученных с полианилином и РРу, связано с тем, что сорбционная емкость РРу значительно выше, чем у полианилина. Эффект повышения удельной поверхности полимера не выявлен, поскольку уже в исходном, необработанном состоянии при данных соотношениях патоген/сорбент РРу полностью сорбирует, как вирусы, так и бактерии.

Регенерация сорбентов. При первичной сорбции, PРy и PPy-Ag практически полностью связывают как вирусы, так и бактерии даже при высоких концентрациях патогенов, и формируют комплекс «сорбент+патоген». Исследование способности к регенерации проводили на сорбентах, которые не подвергались термоактивации, но прошли процедуру первичной сорбции и были выделены из ФР низкоскоростным центрифугированием в виде комплексов с патогеном. Данный комплекс был использован для повторной сорбции патогенов, как в исходном состоянии, так и после различных процедур регенерации: 1 - диспергирования в ФР, 2 - термообработки в ФР при $100^{\circ} \mathrm{C} ; 3$ - воздействия ультразвука в ФР в течение 15 мин. После этого комплекс был выделен из ФР и участвовал в повторной сорбции патогенов. В таблицах 2 и 3 приведены данные о сорбционной активности таких материалов в отношении вирусов и бактерий.

Таблица 2. Эффективность реактивации комплексов (сорбент+вирус)

\begin{tabular}{|c|c|c|c|c|c|}
\hline \multirow[b]{2}{*}{ № } & \multirow[b]{2}{*}{$\mid \begin{array}{c}\text { Комплекс } \\
\text { «сорбент+патоген» }\end{array}$} & \multirow{2}{*}{$\begin{array}{l}\text { Обработка комплекса } \\
\text { «сорбент+патоген» }\end{array}$} & \multirow[b]{2}{*}{ Вирус } & \multicolumn{2}{|c|}{ Титр вируса, ГАЕ } \\
\hline & & & & $\begin{array}{c}\text { до } \\
\text { сорбции }\end{array}$ & $\begin{array}{c}\text { после } \\
\text { сорбции }\end{array}$ \\
\hline 1 & PPy & \multirow{2}{*}{ растворение в ФР } & \multirow{8}{*}{$\begin{array}{c}\text { А/Южная } \\
\text { Каролина/02/ } \\
2010\end{array}$} & \multirow{8}{*}{512} & 32 \\
\hline 2 & PPy-Ag & & & & 64 \\
\hline 3 & PPy & \multirow{2}{*}{ растворение в ФР +УЗ } & & & 32 \\
\hline 4 & PPy-Ag & & & & 32 \\
\hline 5 & PPy & \multirow{2}{*}{$\begin{array}{c}\text { раств. в ФР, прогрев } 30 \text { мин } \\
\text { при } 100^{\circ} \mathrm{C}+\text { У3 (15 мин) }\end{array}$} & & & 16 \\
\hline 6 & PPy-Ag & & & & 8 \\
\hline 7 & PPy & \multirow{2}{*}{$\begin{array}{c}\text { раств. в ФР, прогрев } 60 \text { мин } \\
\text { при } 100^{\circ} \mathrm{C}+\text { У3 }(15 \text { мин })\end{array}$} & & & 16 \\
\hline 8 & PPy-Ag & & & & 8 \\
\hline
\end{tabular}


Таблица 3. Эффективность реактивация комплексов (сорбент + бактерия)

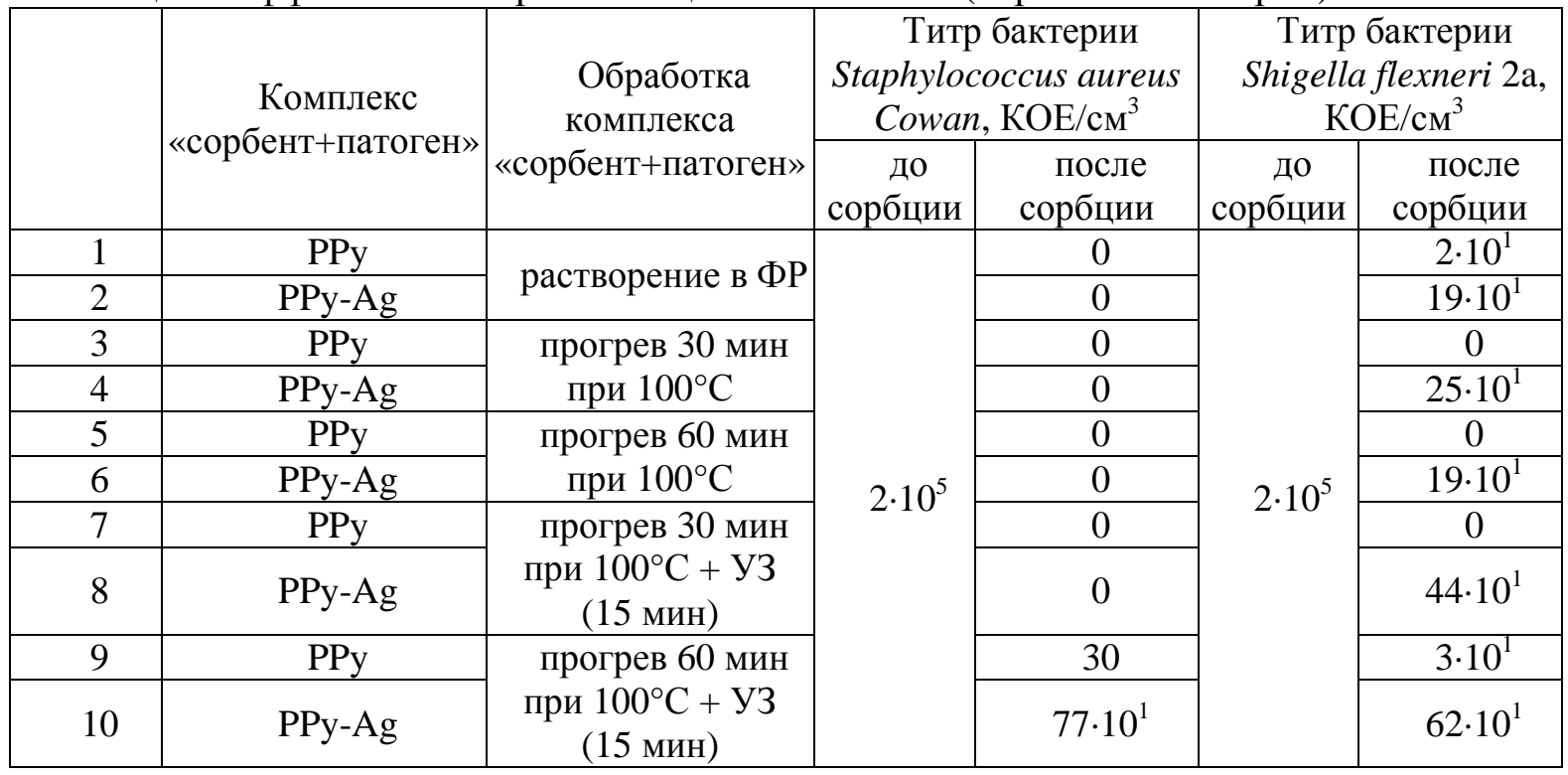

Повторное введение комплексов РРу+вирус и РPy-Ag+вирус в вируссодержащую среду А/Южная Каролина/02/2010 с титром 512 ГАЕ приводит к снижению ГА титра только до 32-64 ГАЕ. Как температурный, так и УЗ фактор в отдельности несколько повышают сорбционную емкость. Так после воздействия УЗ сорбционная активность комплекса PPy-Ag повысилась в 2 раза. Однако наилучший результат получен при сочетании термообработки с последующим воздействием УЗ. Такой метод регенерации приводил к снижению ГА титра до 16-8 ГАЕ, что говорит о целесообразности повторного использования сорбента.

В пользу этого говорит также факт отсутствия инфекционной активности комплексов РРу+вирус гриппа $\mathrm{A}(\mathrm{H} 3 \mathrm{~N} 2)$ на клетках MDCK после прогревании их при $100^{\circ} \mathrm{C}$ и обработки УЗ в течение 15 мин, как было ранее показано в работе [12]. Это свидетельствует об инфекционной безопасности выделенных из раствора комплексов.

В таблице 3 приведены данные о сорбционных свойствах комплекса «сорбент+бактерия» при различных методах его обработки с целью регенерации сорбционной активности. Показано, что комплекс участвует в повторной сорбции как граммположительных, так и граммотрицательных бактерий, снижая их КОЕ титры от эпидемически опасных КОЕ $2 \cdot 10^{5}$ до безопасных значений. При этом эффективность сорбции не зависела от методов обработки комплекса. Даже сорбент, прошедший первичную сорбцию и редиспергированный в ФР, демонстрирует значительное снижение титра КОЕ при повторной сорбции, что говорит о его высокой сорбционной активности по отношению к бактериям. Из данных таблицы 3 видно, что сорбенты имеют разное сродство к бактериям рода Staphylococcus и Shigella. Staphylococcus aureus сорбируется и дезактивируется полимером практически полностью, тогда как в случае Shigella flexneri присутствуют следы жизнеспособных бактерий.

Вопрос о механизме сорбции полипирролом биологических материалов и причине различного сродства к тем или иным белковым структурам остается открытым. Биологические объекты, используемые в данной работе, имеют разные формы и размеры, различаются видом нуклеиновых кислот, структурой белков, в том числе и поверхностных, важных для взаимодействия с сорбентом. Так вирусы гриппа А (H1N1) pdm09 являются РНК содержащим вирусом, имеют полиаморфную форму и 
содержат наружные белки гликопротеиды, погруженные в липопротеиновую мембрану. Бактерия Staphylococcus aureus Cowan (Грам +) имеет кокковидную форму. В наружной оболочке Staphylococcus присутствует пептидогликан, представляющий собой смешанные углевод-белковые полимеры, соединенные ковалентными связями с тейхоевыми кислоты, тейхуроновыми кислотами и липопротеинами. Бактерия Shigella flexneri 2a (Грам -) имеет палочковидную форму. Отличительной особенностью строения клеточной стенки энтеробактерий, в том числе шигелл, является наличие внешней мембраны, основным компонентом которой являются липопротеиды. Специфическим компонентом наружной мембраны Shigella является липополисахарид сложного молекулярного строения, который локализован во внешнем слое и занимает около 30-40\% ее поверхности [13]. Цитоплазматическая мембрана представлена гидрофобной зоной фосфолипидов, которую принизывают белковые тяжи. Бактерии Shigella flexneri 2а снабжены филаментозными образованиями - ресничками, расположенными по всей поверхности клетки, которые обеспечивают выраженные адгезивные свойства бактериям. Генетический контроль синтеза компонентов бактериальных клеток Грам+ и Грам- бактерий детерминируется генами хромосомы и плазмид. При взаимодействии с полимерами различия в структуре микроорганизмов могут приводить к различию в сорбции.

Сам процесс связывания микроорганизма сорбентом также не является элементарным актом. С помощью фазово-контрастной микроскопии выявлены две фазы сорбции бактерий на углеродный волокнистый сорбент. В первой фазе длительностью 1-2 минуты происходило прикрепление немногочисленных бактерий к поверхности сорбента. И только во второй фазе наблюдали образование устойчивых скоплений бактериальных клеток рядом с поверхностью. Авторы полагают, что бактерии вырабатывают некие лигандные вещества, которые определяют основной механизм сорбции на носитель [14]. Сложная структура и организация биологических объектов не позволяет пока говорить о причинах их взаимодействия с сорбентом.

\section{Заключение}

Настоящее исследование показало, что сорбенты РРу и РРу-Ag после первичной сорбции микропатогенов (бактерий и вирусов) из водных сред могут быть регенерированы путем кратковременного прогрева в воде с последующим ультразвуковым воздействием и пригодны для повторного применения. Преимуществами данных сорбентов при их использовании для очистки водных сред от биологических загрязнений являются: 1) способность эффективной сорбции широкого спектра микропатогенов: как бактерий, так и вирусов; 2) подавление инфекционной активности связанных микропатогенов, т.е. полная инфекционная безопасность комплексов «сорбент+патоген»; 3) возможность регенерации и многократного применения сорбента. В тоже время, данные сорбенты нетоксичны и сравнительно дешевы.

Работа выполнена при финансовой поддержке гранта РНФ № 19-73-30003

\section{Список литературы}

1. Буханов В.Д., Везенцев А.И., Пономарева Н.Ф. и др. // Научные ведомости Белгородского государственного университета. Серия естественные науки. 2011. № 21 (116). Вып. 17. С. 57-62.
2. Pandey S.S., Gerard M., Sharma A.L., Malthora B.D. // Journal of Applied Polymer Science. 2000. Vol. 75. pp. 149-155. 
3. Lundin V., Herland A., Berggren M. et al. // www.plosone.org April 2011. Vol. 6. Issue 4. е18624 (дата обращения 4.05.2019).

4. Sapurina I., Lia Y., Alekseeva E. et al. // Polymer. 2017. Vol. 113. pp. 247-258. https://doi.org/10.1016/j.polymer.2017.02.064.

5. Benabderrahmane S., Bousalem S., Mangeney C. et al. // Polymer. 2005. Vol. 46. pp. 1339-1346.

6. Smith A.B., Knoweles C.J.// J. Appl. Polym. Sci. 1991. Vol. 43. pp. 399-403.

7. Azioune A., Chemini M.M., Miksa B. et al. // Langmuir. 2002. Vol. 18. pp. 1150.

8. Saoudi B., Jammul N., Chehimi. M.M. et al. // Spectroscopy. 2004. Vol.18. pp. 512-525.

9. Singh R., Chandra S., Singh H., Narula A.K., Broor S. Conducting polymer membrane and a process for the preparation of the same

\section{References}

1. Bukhanov V.D., Vezentsev A.I., Ponomareva N.F. et al., Nauchnye vedomosti Belgorodskogo gosudarstvennogo universiteta. Seriya estestvennye nauki, 2011, Vol. 17, No 21 (116), pp. 57-62.

2. Pandey S.S., Gerard M., Sharma A.L., Malthora B.D., Journal of Applied Polymer Science, 2000, Vol. 75, pp. 149-155.

3. Lundin V., Herland A., Berggren M. et al., www.plosone.org April, 2011, Vol. 6, Issue 4, e18624(4.05.2019).

4. Sapurina I., Lia Y., Alekseeva E. et al., Polymer, 2017, Vol. 113, pp. 247-258. https://doi.org/10.1016/j.polymer.2017.02.064.

5. Benabderrahmane S., Bousalem S., Mangeney C., et al., Polymer, 2005, Vol. 46, pp. 1339-1346.

6. Smith A.B. and Knoweles C.J., J. Appl. Polym. Sci,. 1991, Vol. 43, pp. 399-403.

7. Azioune A., Chemini M.M., Miksa B. et al., Langmuir. 2002, Vol. 18, pp. 1150.

8. Saoudi B., Jammul N., Chehimi. M.M. et al., Spectroscopy, 2004, Vol. 18, pp. 512-525.

Морозова Екатерина Олеговна - научный сотрудник, лаб. лаб. этиологии и эпидемиологии гриппа ФГБУ «Национальный исследовательский центр эпидемиологии и микробиологии имени почетного академика Н. Ф. Гамалеи» Минздрава России, «НИЦЭМ им. Н.Ф. Гамалеи» Минздрава России, Москва

Кулик Екатерина Андреевна - студент 3 курса ФГАОУ ВО Первый МГМУ имени И. М. Сеченова Минздрава России, Москва membrane. Patent USA. Publication number US6156202 A. 1999. https://www.google.com/patents/US6156202.

10.Гарина Е.О., Иванова В.Т., Носик Н.Н. и др. // Нанотехнология: разработка и применение. ХХІ век. 2016. Т. 8. № 2. С. 3-13.

11.Иванова В.Т., Гарина Е.О., Николаева Т.Н. и др. // Вода: химия и экология . 2016. № 10. C. 71-81.

12.Иванова В.Т., Гарина Е.О., Сапурина И.Ю. // Сорбиионные и хроматографические проиессы. 2017. Т. 17. № 4. С. 592-600.

13.Нетрусов А.И., Котова И.В. М. // Общая микробиология: ИЦ «Академия». 2007. С. 2527.

14.Зинин-Бермес Н.Н., Шишлянникова Н.Ю., Ковтун В.П. // Медицина в Кузбассе. 2004. № 3. C. 24-26.

9. Singh R., Chandra S., Singh H., Narula A.K., Broor S. Conducting polymer membrane and a process for the preparation of the same membrane. Patent USA. Publication number US6156202 A. 1999. https://www.google.com /patents/US6156202.

10. Garina E.O., Ivanova V.T ., Nosic N.N. , Kondrashina N.G et al., Nanotekhnologiya: razrabotka i primenenie. XX1 vek, 2016, Vol. 8, No 2, pp. 3-13.

11. Ivanova V.T., Garina E.O., Nikolaeva T.N., Suetina I.A. et al., Voda: khimiya i ekologiya, 2016, No 10, pp.71-81.

12. Ivanova V.T., Garina E.O., Sapurina I.Yu., Stejskal J. et al., Sorbtsionnye i khromatograficheskie protsessy, 2017, Vol. 17, No 4, pp. 592-600.

13. Netrusov A.I. Cotova I.V., Obshchaya mikrobiologiya: ITS «Akademiya», 2007, pp. 25-27.

14. Zinin-Bermes N.N., Shishlyannikova N.Y., Kovtun V.P., Meditsina v Kuzbasse, 2004, No 3, pp. 24-26.

Morozova Ekaterina O. - $\mathrm{PhD}$ (virology) researcher, Lab of etiology and epidemiology of influenza Federal State Budgetary Institution «National Research Center for Epidemiology \& Microbiology named after the honorary academician N.F. Gamaleya» of the Ministry of Health of Russian Federation, Moscow

Kulik Ekaterina A. - student of 3 cours of A.I.M. Sechenov First Moscow State Medical University, Moscow 
Сапурина Ирина Юрьевна - д.Х.н., ведущий научный сотрудник, лаб. Анизотропных и структурированных полимерных систем, Институт Высокомолекулярных соединений РАН, СанктПетербург

Николаева Татьяна Николаевна - д.м.н., (ведущий научный сотрудник, лаб естественного иммунитета, ФГБУ «Национальный исследовательский центр эпидемиологии и микробиологии имени почетного академика Н. Ф. Гамалеи» Минздрава России, «НИЦЭМ им. Н.Ф. Гамалеи» Минздрава России, Москва

Бурцева Елена Ивановна - д.м.н., (вирусология) Рук. лаборатории этиологии и эпидемиологии гриппа ФГБУ «национальный исследовательский центр эпидемиологии и микробиологии имени почетного академика Н. Ф. Гамалеи» Минздрава России, «НИЦЭМ им. Н.Ф. Гамалеи» Минздрава России, Москва

Пронин Александр Васильевич - д.б.н., (иммунология) проф. Рук. лаборатории естественного иммунитета ФГБУ «Национальный исследовательский центр эпидемиологии и микробиологии имени почетного академика Н. Ф. Гамалеи» Минздрава России, «НИЦЭМ им. Н.Ф. Гамалеи» Минздрава России г. Москва «НИЦЭМ им. Н.Ф. Гамалеи» Минздрава России, Москва

Иванова Валерия Тимофеевна - д.б.н., ведущий научный сотрудник, лаб. этиологии и эпидемиологии гриппа ФГБУ «Национальный исследовательский центр эпидемиологии и микробиологии имени почетного академика Н. Ф. Гамалеи» Минздрава России, «НИЦЭМ им. Н.Ф. Гамалеи» Минздрава России, Москва
Sapurina Irina Yu. - Dr.Sci. (Chem), Leading researcher, Lab Laboratory of anisotropic and structureted polymer sistems, Institute of Macromolecular Compounds, Russian Academy of Sciences, Saint-Petersburg

Nicolaeva Tatiyna N. - Dr.Med .Sci( microbiology) Leading researcher, Lab Natural Immune System, «N.F. Gamaleya NRCEM», Moscow

Burtseva Elena I. - Dr.Med.Sci(virology), Head of the Lab. of etiology and epidemiology of influenza, «N.F. Gamaleya NRCEM», Moscow

\section{Pronin Alexander V.}

Dr.Sci(Immunology)prof Head of the Lab Natural Immune System «N.F. Gamaleya NRCEM», Moscow

Ivanova Valeria T. - Dr.Sci.(virology) Leading researcher, Lab of etiology and epidemiology of influenza, «N.F. Gamaleya NRCEM», Moscow 